\title{
"Sisters in Law": desafios das mulheres pioneiras no Direito nos Estados Unidos da América e no Canadá
}

\section{"Sisters in Law": Women Pioneers in Law in USA and Canada}

\author{
Gunter $\mathrm{Axt}^{1}$
}

\begin{abstract}
Submetido em 22 de novembro e aprovado em $1^{\circ}$ de dezembro de 2017.
\end{abstract}
\begin{abstract}
Resumo: O artigo propõe-se a oferecer uma perspectiva de síntese de aspectos relacionados ao princípio da trajetória feminina nas profissões jurídicas na América do Norte, sobretudo nos Estados Unidos, mas também no Canadá, das últimas décadas do século XIX aos primeiros anos do século XX. O texto apoia-se em bibliografia publicada em inglês e pouco conhecida no Brasil, procurando articular uma compreensão dos desafios de gênero que marcaram as primeiras gerações de mulheres operadoras do Direito, esforço que pode ser de grande utilidade para fins comparativos com a realidade de outros países e regiões. Nesse sentido, são discutidas desde aspectos relativos à indumentária prescrita para o ambiente tribunício, até os desafios inerentes à emergência do ensino misto.
\end{abstract}

Palavras-chave: Gênero. Mulheres. Direito. Estados Unidos. Século XIX. Feminismo. Profissões jurídicas. Ensino jurídico. Educação mista.

Abstract: The article proposes to offer a perspective of synthesis of aspects related to the
beginning of the female trajectory in the legal professions in North America, especially
in the United States, but also in Canada, from the last decades of the nineteenth century
to the first years of the twentieth century. The text is based on a bibliography published
in English and very little known in Brazil, seeking to articulate an understanding of the
gender challenges that marked the first generations of women operating law, an effort
that can be very useful for comparative purposes with the reality of others countries and
regions. In this sense, it is discussed from aspects related to the clothing prescribed for the
tribune and bar environment, to the challenges inherent in the emergence of coeducation.

Keywords: Gender. Women. Law. United States. Nineteenth century. Feminism. Coeducation.

Em 2011, em passagem por São Paulo, onde participava do III Congresso da revista Cult, o filósofo esloveno Slavoj Zizek relacionou dois filmes, que aparentemente nada tinham em comum, então destacados na consagrada premiação do Oscar: $O$ discurso do rei e Cisne negro. Espremida a história de ambos, notou, o primeiro conta a trajetória de um homem sem qualquer desenvoltura que enfrenta todos os obstáculos pessoais para se afirmar no espaço público, apoiado por uma mulher inteligente e compreensiva (mas 
sem protagonismo), e acaba obtendo sucesso e comovendo os que o cercam, enquanto o segundo representa a desventura de uma moça talentosíssima que, ao alcançar o estrelato, se destrói em autocomsumpção, numa espécie de histeria vitoriana em plena era pósmoderna. Os dois filmes, percebidos em cotejo, seriam, assim, reveladores de um traço ideológico da sociedade, que ainda hoje se insinuaria tacitamente: quando as mulheres foram para o mercado de trabalho formal, fora de casa, se esperaria delas, de forma difusa, talvez, serem cisnes negros em terras de reis gagos (AXT, 2017).

O insight pode dar pistas para a compreensão de fenômenos tais como o elevado padrão de cobrança autoimposto por muitas pioneiras no mercado de trabalho, ou o contraste entre a presença já expressiva das mulheres no primeiro grau das profissões da Justiça, tanto no Judiciário, quanto no Ministério Público, e a sua participação aguada, numericamente tímida, na alta Administração da maior parte de instituições jurídicas, isto é, o território onde a competência profissional se combina com a desenvoltura política na construção de uma narrativa para o espaço de poder (AXT, 2017).

Para Zizek (2011), com efeito, a eficácia de uma ideologia seria proporcional a sua capacidade de não se fazer notar. É o que Pierre Bourdieu (1999: 7) chamaria de “paradoxo da doxa”, no preâmbulo do seu clássico $A$ dominação masculina, isto é, que a ordem do mundo, estabelecida com seus direitos, imunidades e privilégios, seja grosso modo respeitada a priori, sem maiores insubordinações, dispensando justificativas, numa espécie de "submissão paradoxal" que resultaria de uma "violência simbólica" contra aqueles que estariam fora do nicho de privilégios.

Mas convém prestar atenção em que aquilo que a teoria oferece com uma mão, pode tirar com a outra. O próprio Bourdieu (1999: 101) convoca os pesquisadores interessados numa história das mulheres a ir além dos grandes modelos interpretativos, debruçando-se sobre a história dos agentes e das instituições, que replicariam, mais ou menos conscientemente, os padrões hierárquicos. Hierarquias, outrossim, não são apenas reproduzidas e construídas. Também são descontruídas, reinventadas, enfrentadas coletiva e/ou individualmente, eventual ou sistematicamente, ao nível do cotidiano. Ideologias ou feixes de reprodução hierárquica, por mais longevos e diacrônicos que sejam, não são engrenagens irremediavelmente aplastantes, das quais não há. Tampouco 
podem os indivíduos ser interpretados de forma essencialista e reducionista. Para Félix Guattari (1992: 19), que se ampara no conceito de subjetividade polifônica de Mikhail Bakhtin, com efeito, os componentes de subjetivação do indivíduo são parciais e heterogêneos, expondo-o a múltiplas influências, a diversas formações discursivas, o que oportuniza margem de invenção. Para o filósofo Henri Bergson (2006), por mais estáveis que pareçam os mecanismos de subjetivação, a imponderabilidade do tempo sempre se insinua, pois a transformação está no devir e o espaço de criação se estabelece no plano da ação pragmática do indivíduo.

Destarte, a história das instituições e das relações de poder, segundo o historiador português António Manuel Hespanha, tem cada vez mais dirigido seu lume para os "poderes efetivos", percebendo os indivíduos como "motores da história" (e não mais as leis, o Direito ou as classes sociais), procurando captá-los numa espécie de geometria inter-relacional, micromodelizada, adaptada aos lugares, aos contextos. Nada a ver, com certa concepção pós-moderna de História ultrafragmentada e, a tal ponto relativizada, que nada mais lhe cabe dizer. O poder, aqui, "interpessoaliza-se, depende dos fatores moles que movem o interior de nós mesmos - os afetos, os poderes de sedução, as hegemonias, as dependências emocionais, os encantamentos, os aborrecimentos de toda a espécie, a beleza e a fealdade". (2012: 69-70). O poder social, como ensina ainda Hespanha (2012: 73), não se exprime de forma monótona. Sua visibilidade, suas formas de hegemonia e os mecanismos de dependência que engendram encerram enorme diversidade, não podendo ser reduzido a modelo único.

Como registra Elizabeth Jelin (2000), em torno de um fato estabelecem-se múltiplas narrativas que disputam o sentido do vivido, o que faz da memória um espaço de luta simbólica. Não se pretende escorregar numa espécie de relativismo subjetivo, como aquele criticado por Beatriz Sarlo (2007) por atribuir foros de verdade a priori a qualquer testemunho, pelo simples fato de ser um depoimento. A memória é feita de um feixe de opiniões, sentimentos, verdades, silêncios, ocultações e embates. Acessar as múltiplas vibrações em torno das vozes da memória nos ajuda a tecer uma percepção mais tangível do complexo passado exalado da inesgotável diversidade do humano. A 
narrativa humana é feita de tentativas, ensaios, fracassos, êxitos, faltas, conquistas, algo que testemunhos mnemônicos podem nos ajudar captar (AXT, 2014).

"Cherchez la femme”: o célebre aforismo que Alexandre Dumas (pai), cinzelado em 1854 no seu Les Mohicans de Paris, ganhou coro ao longo do século XIX e do XX. No âmbito do Direito e da Medicina Legal, foi replicado pelo criminologista italiano Cesare Lombroso, quem, a propósito, considerava a criminalidade feminina ainda mais monstruosa do que a praticada pelos homens, ligando-a aos ciclos biológicos da mulher. De qualquer forma, a ideia de que na raiz do problema há sempre a urdidura de uma essência feminina, corrosiva, deletéria e irracional, espelha a matriz polissêmica do conceito de poder no plano ideológico mais amplo: em maiúsculo e no singular designa o espaço público, território da ordem e da razão, apanágio masculino, mas quando em minúsculo e no plural, se estilhaça em múltiplas influências difusas, território sub-reptício no qual reinam as mulheres. Nesse horizonte, o homem público encarnaria a honra e a virtude; a mulher pública constituiria a vergonha, é a parte dissimulada, noturna, escondida - um território de passagem sem individualidade própria. Um é o político de renome, o grande magistrado; a outra é a meretriz (PERROT, 2010: 167-175).

Ao longo do século XIX aprofundou-se o discurso de divisão das tarefas e de segregação sexual dos espaços. O filósofo Hegel falava em "vocação natural” dos dois sexos e Auguste Comte foi mais longe ao preconizar a "inaptidão radical do sexo feminino para o governo, mesmo da simples família”. (PERROT, 2010: 178). "Baseado na crença de uma natureza feminina, que dotaria a mulher biologicamente para executar as funções da esfera da vida privada, o discurso é bastante conhecido: o lugar da mulher é o lar, a sua função consiste em casar, gerar filhos...” (MALUF; MOTT, 1998). Na vida privada, a figura obcecante da maternidade reveste, contudo, a mulher de potência civilizadora, vibrada no diapasão das funções educadora e cuidadora (PERROT, 2010: 169; BEAUVOIR, 2009).

Mas se esse é o discurso hegemônico, na prática as relações que se estabelecem no cotidiano podem se revestir de feição mais aperiódica e irridente. As mulheres não foram passivas nem submissas, mas se afirmaram por outras palavras, gestos, traçando caminhos diversos, adaptando-se, tentando furar barreiras, percurso este nem sempre 
representado nas fontes dominantes, ou na forma como elas tendem a ser interpretadas (PAGLIA, 1990; PERROT, 2010: 185, 212).

A historiadora Camille Paglia conclui que mesmo na conservadora sociedade do Antigo Egito, uma mulher poderia desenvolver funções públicas; e que as famosas cariátides da Acrópole da Atenas clássica são "uma admirável exibição de potência feminina" (2014: 8, 21-25). O arqueólogo Fábio Vergara Cerqueira, por sua vez, mostra como uma nova historiografia que se desenvolve, sobretudo a partir do último quartel do século XX, vem redescobrindo a participação feminina no espaço público na Grécia Antiga, território de emulação da origem do discurso misógino ocidental, identificando, por meio do estudo das fontes iconográficas, os rastros de mulheres de classes populares economicamente ativas, bem como de cidadãs privilegiadas assumindo funções cívicas no âmbito religioso, inclusive disputando cargos eletivos, o que há não muito tempo seria considerado um delírio pelos historiadores (CERQUEIRA, 2008: 158).

Michelle Perrot sublinha que os motins por alimentos na França do século XIX foram em geral animados e despoletados por mulheres, que hauriam a sua legitimidade na ideia de guardiãs dos víveres e do teto, oportunidades nas quais elas intervinham coletivamente, rosto descoberto, lançando projéteis, guardados nos bolsos dos seus aventais, tais como pedras ou artigos de mercado, e vituperando insultos, aos gritos, numa grande balbúrdia. São bem conhecidos os traumas do sangrento charivari iniciado no mercado de Les Halles pelas peixeiras, em cinco de outubro de 1789, que culminou com a transferência da família real do idílico retiro aristocrático de Versalhes para o burburinho do abandonado palácio das Tulherias, no coração de Paris, elevando a Revolução Francesa a um patamar mais potente (APPLEWHITE; LEVY, 1984): “Onde está o 'povo', a mulher está energicamente presente", com sua linguagem subversiva, irônica e irreverente, valendo-se de toda "uma rede de comunicações horizontais que escapa aos ouvidos do poder", usando estratégias de inversão e de derrisão, algo que a nova moral burguesa do século XIX foi cada vez tolerando menos. Na Inglaterra, foi por volta de 1850 que os pubs começaram a se tornar lugares de frequência exclusivamente masculina, pois, até então, as mulheres bebiam e cantavam com os seus homens nas tavernas. Na França, o sindicalismo foi progressivamente recusando as formas tradicionais de expressão reivindicatória das 
mulheres em público, compreendendo-as como inadequadas à dignidade pretendida aos trabalhadores (PERROT, 2010: 199, 206, 211).

No século XIX, o cotidiano assume valor positivo e as mulheres cada vez mais regram o tempo doméstico. A cronologia da vida feminina era pautada na França burguesa, assim como alhures, pela primeira comunhão, pelo noivado e pelo casamento, dinâmica expressa na moda dos álbuns de fotografias, hábito que ritualiza o tempo e as vivências familiares, pelo menos antes de sua banalização. Se o tempo dos homens é o da vida pública, a vida privada é o seu refúgio, onde descansam do esforço profissional (MARTIN-FUGIER, 1991).

Até onde se sabe, as primeiras mulheres a conseguirem atuar no Direito em tempos modernos foram estadounidenses. "Gentleman M.B." aparece nos registros dos Estados Unidos em 1638 como fazendeiro, liderança local e advogado. Mas o que não estava explícito é que esse cavalheiro era de fato uma mulher: Margaret Brent, que foi a primeira a ser provisionada para advogar junto a um tribunal. Seriam necessários mais de 200 anos para que outras repetissem a façanha: Em 1869, Myra Bradwell (Illinois), Mary Magoon (Iowa) e Belle Mansfield (Iowa) requisitaram acesso à comunidade jurídica (MORELLO, 1986: 8-9).

Como notaram Virginia Drachman (1998: 2-3) e Cynthia Epstein (1981: 20-25), a história das mulheres no Direito é diferente daquela das mulheres em outras profissões, porque essa era a área de saber mais cerrada ao gênero feminino e um campo no qual a masculinidade foi parte fundante da identidade da profissão. Em 1920, nos Estados Unidos, as mulheres eram $86 \%$ das professoras de escolas primárias, $66 \%$ dos assistentes sociais, $5 \%$ dos médicos, mas apenas 1,4\% dentre todos os advogados. Em 1970, ainda representavam $2 \%$ dos profissionais em Direito, porcentagem que saltou para $12 \%$, em 1980 e quase $32 \%$, em 2008, segundo dados apurados por Jessica Nelson. Nos cursos jurídicos, as mulheres representam hoje $47 \%$ dos estudantes nos Estados Unidos (NELSON, 2010: 1).

No vizinho Canadá. Estimava-se que em 2008 37\% dos profissionais do Direito eram mulheres, sendo que $1 \%$ de todos os advogados eram mulheres aborígenes. Em 2014, metade dos bacharéis que ingressam nas profissões jurídicas eram mulheres. No Quebec, elas já são mais de 60\% (CATALYST, 2015). 
Nos Estados Unidos, já em 1849 uma mulher conseguira se formar em Medicina, disciplina que, apesar das resistências, foi de certo modo considerada um desdobramento lógico da natureza feminina devotada à assistência, sem mencionar o fato de que os pudores do século XIX faziam com que muitas damas rejeitassem serem examinadas por médicos do sexo masculino. Mas as conquistas de algumas no campo da Medicina estadunidense estavam longe e ser a regra: a primeira médica canadense precisou se formar nos Estados Unidos, em 1867 (AXT, 2017).

Para Karen Morello (1986: 76), ao mesmo tempo em que no século XIX se acirrava o discurso que procurava restringir os direitos cívicos das mulheres, atando-as às atividades domésticas, os reflexos da Revolução Industrial as impulsionavam para fora de suas casas, pois foram requisitadas como mão de obra nas fábricas, nos hospitais e nos escritórios. Além disso, os crescentes confortos da vida moderna passaram a conceder às donas de casa um tempo extra, que poderia ser investido na leitura e nos estudos, por exemplo. Camille Paglia (1992: 7), a propósito, notou esse paradoxo numa perspectiva ainda mais ampla, pois atribui à cultura patriarcal, em contraste com tempos ainda mais antigos, a forja de uma ambiência de relativa paz urbana que permitiu às mulheres saírem de casa sem serem massivamente violentadas.

Nos Estados Unidos, a consolidação da marcha para o Oeste abriu um espaço para absorção de mão de obra feminina em todos os tipos de atividades, o que teria sido aproveitado pelas pioneiras no Direito. Finalmente, naquele país, as mulheres teriam se beneficiado do movimento abolicionista, que incorporou o conceito de equidade para além dos negros, alcançando-as. De resto, nos períodos de conflagração, como a Segunda Guerra Mundial e a Guerra da Coreia, quando muitos homens foram enviados ao front de batalha, as barreiras à educação mista nas universidades foram relaxadas e o número de mulheres estudantes de Direito aumentou conjunturalmente (NELSON, 2010: 9).

Ao longo desse percurso, o acesso à profissão jurídica foi obtido por meio de instituições controladas por homens, tais como tribunais, associações de magistrados, escolas de Direito: a profissão que escolheram fazia e interpretava as leis que negavam o seu acesso aos direitos de cidadania, incluindo a prática do Direito. No momento em que tentaram integrar a profissão jurídica, as mulheres se confrontaram com uma tensão entre 
gênero e identidade profissional, o que as advogadas do século XIX denominaram de "o fardo da dupla consciência"(DRACHMAN, 1998: 2-3).

Poucas escaparam a essa tensão. Como estudantes de Direito, por exemplo, se debateram com a dúvida entre falar espontaneamente como faziam os rapazes nas salas de aula ou recolherem-se recatadamente, como se esperava das damas. Nas cortes e nos júris, deveriam retirar o chapéu, como determinava o código de posturas para os advogados, ou mantê-los, como faziam em público as senhoras daqueles tempos? Dramas como estes eram discutidos entre as pioneiras, muitas vezes em cartas, trocadas no âmbito de um clube de advogadas, chamado Equity Club, que funcionou no final dos anos 1880 (DRACHMAN, 1998: 95), suscitando muitas questões que permaneceram em aberto ao longo do século XX, não apenas nos Estados Unidos, mas também em outros países.

Porque as respostas das pioneiras não necessariamente se pautavam pelo enfrentamento, mas pela tentativa de acomodação, de ocupação de espaços como numa guerra de posições; Michael Grossberg (1990: 133-148) chegou a sustentar, injustamente, que elas ingressaram na profissão sem desafiar as premissas de gênero que regravam o mundo ao seu redor. Mas o fato é que a simples presença de uma mulher defendendo um réu num Tribunal do Júri era já desestabilizadora dessas premissas...

Em 1869, a Sra. Bradwell, esposa de um eminente juiz e deputado e fundadora do hebdomadário de sucesso Chicago Law News (CHESTER, 1985: 88; GORECKI, 1990), peticionou, junto à Suprema Corte de Illinois, o direito de advogar e ouviu como resposta: "Deus desenhou os sexos para preencher diferentes esferas de ação, pertencendo aos homens o dever de fazer, questionar e executar as leis". A Corte ignorou o precedente de Mansfield, em Iowa e rejeitou a candidatura de Bradwell, sobretudo porque ela era casada. Um juiz chegou a argumentar que o marido de uma advogada, que eventualmente gerisse mal os fundos ou as causas de um cliente, poderia ser responsabilizado pelos prejuízos. Em 1875, o Juiz Ryan, da Suprema Corte de Wisconsin sentenciou: “a lei da Natureza destina e qualifica o sexo feminino para manter e amamentar as crianças da nossa espécie e para custodiar os lares do mundo, garantindo a sua manutenção no amor e na honra. [...] Admitir mulheres advogando seria emascular a Constituição”. Esta “jurisprudência das esferas separadas” era ancorada na própria tradição reinterpretada da 
Common Law, segundo a qual mulheres casadas não dispunham de independência legal de seus maridos, além de cotidianamente incensada na camaradagem cerzida entre juízes e advogados, que reforçava a ideia de inadequação das mulheres ao ambiente jurídico. A imagem de uma Constituição emasculada revela o quanto se temia que a autorização para advogar implicasse a subversão da hierarquia doméstica e a extensão às mulheres do direito ao voto (DRACHMAN, 1998: 9-18).

Diante da resistência da Corte Estadual, Bradwell, amparando-se na $14^{\mathrm{a}}$ Emenda, que garantia direitos iguais a todos os cidadãos em território estadunidense, resolveu tentar a sorte em apelação à Suprema Corte dos Estados Unidos. A decisão, em 1873, estabeleceu não estarem as mulheres garantidas pelas mesmas imunidades e privilégios que a Constituição estendia aos cidadãos do sexo masculino. A Corte recusou-se a identificar, em Bradwell v. State of Illinois, como uma questão de gênero, para reduzir o caso a uma disputa em torno de uma simples licença, motivo pelo qual repassou às Assembleias Estaduais a competência para legislar sobre a matéria. A decisão complicou a situação, pois criou uma jurisprudência para dois níveis de cidadania. A partir daí, as pretensões femininas encontraram novas barreiras e sua luta se fragmentou, pois precisava ser ganha em cada Estado, em cada trincheira. A Associação dos Tribunais da Cidade de Boston, por exemplo, não aceitou mulheres como membros até 1916. (DRACHMAN, 1998: 19-36). E, mesmo no Canadá, o caso Bradwell foi citado com frequência pelos tribunais para justificar a negação da licença de atuação às mulheres nas duas primeiras décadas do século XX (MOSSMAN, 2007: 384).

Contudo, entre 1882 e 1893, uma nova jurisprudência da integração foi aos poucos substituindo a das esferas separadas, constituindo-se no primeiro sucesso das mulheres em utilizar o sistema judicial para modificar o seu status legal na sociedade. A ideia que se tornou predominante era que se um estatuto não expressasse claramente a limitação de uma liberdade, então era porque essa limitação não existia. A maior parte dos Estados foi entendendo não haver restrição explícita para que as mulheres falassem em público ou assumissem responsabilidades públicas. Entre 1888 e 1923, 20 das 21 Cortes Estaduais americanas admitiram a advocacia feminina (DRACHMAN, 1998: 19-36). 
Paralelamente, no Canadá. Clara Brett Martin conquistava em 1897 o direito de advogar, depois de um exaustivo debate com a Law Society of Upper Canada. Em 1891, depois de se graduar aos 16 anos de idade, em Bachelor of Arts in Mathemathics, uma espécie de curso com quatro anos de duração com foco em artes liberais (retórica, gramática, lógica, aritmética, geometria, ciências...), Martin solicitou à Law Society uma licença para se tornar um membro estudante, condição para alcançar o grau de solicitador, o que lhe permitiria atuar na advocacia com a orientação de um advogado reconhecido (no Brasil, por exemplo, a função existia ainda nos anos 1960 e era condição facultada aos quintanistas, ou seja, aos estudantes do último ano do curso de Direito). A sociedade concluiu que apenas “pessoas” poderiam advogar e mulheres não eram então reconhecidas como sujeitos de direito no Canada.

A causa de Martin não ficou, contudo, enclausurada. Foi logo apoiada por mulheres proeminentes, como Emily Stowe, primeira médica a atuar no Canadá, que se formara nos Estados Unidos e passara a se dedicar a defesa dos direitos das mulheres, e Lady Ishbel Aberdeen, uma nobre militante feminista, cujo influente esposo foi Governador-Geral do Canadá entre 1893 e 1898. Lady Aberdeen organizou o National Council of Women of Canada, braço local da International Council of Women, entidade criada pelas sufragistas estadounidenses na década anterior. No Legislativo de Ontario, W.D. Balfour promoveu um projeto de lei para reconhecer que a condição de pessoa nas sociedades jurídicas deveria contemplar homens e mulheres. Em seguida, com o apoio do Premier de Ontario, Sir Oliver Mowat, aprovou-se em 13 de abril de 1892 uma legislação que admitia a atuação de mulheres como solicitadores. Em 1897, Martin foi admitida como advogada junto ao Tribunal de Ontario. Em 1899, a Universidade de Toronto concedeu-lhe o grau de LLB in Law, o primeiro estágio de graduação em Direito no sistema universitário do país, que autoriza uma pessoa a tornar-se efetivamente advogado. Como muitas mulheres de seu tempo, Martin optou por permanecer solteira, a fim de poder seguir no exercício da carreira (DICTIONARY, 1979-2016; BACKHOUSE, 1985, 1992; COSSMAN; KLINE, 1992).

Assim, no Canadá, a demanda pelo exercício da advocacia e a questão da coeducação jurídica chegaram juntas e cerca de 20 anos mais tarde do que nos Estados Unidos, encontrando já um terreno menos adusto, pois o movimento sufragista e feminista 
já se organizava internacionalmente, mulheres e políticos influentes apoiaram a causa e, no pais vizinho, já havia precedentes. Clara abriu caminho para a atuação feminina no Direito não apenas no Canadá, mas na Commonwealth britânica. Porém, como de resto acontecia em todo o mundo, a vitória de Martin ainda estava longe de se converter em uma conquista coletiva sedimentada. Basta lembrar que o Canadá apenas garantiu o voto feminino, em nível federal, em 1918, depois da vitória do movimento sufragista nas Províncias de Manitoba, Alberta e Saskatchewan, em 1916, seguidas por Ontario, em 1917. No Quebec, as mulheres tiveram o direito ao voto negado até 1940. Mulheres das populações autóctones apenas ganharam o direito de votar na década de 1960. Nas profissões jurídicas, as mulheres progrediram lentamente. Em 1990, se metade dos graduandos em Direito já eram mulheres, elas perfaziam apenas 20\% dos agentes nos tribunais canadenses (BROOKS; MATHEN, 2010; FARADY; DENIKE; STEPHENSON, 2009).

Quando a presença feminina no Direito começou a parecer irreversível, passou-se a discutir o perfil mais adequado a uma mulher que pretendia seguir carreira jurídica. Um exemplo interessante são os debates travados em Harvard em torno das candidatas com o supostamente melhor perfil para enfrentar as barreiras de gênero e lograr aceitação de seu pedido de inscrição na prestigiosa universidade. Em 1899, Francis Keay, apesar de seu bom background educacional, foi considerada portadora de certa ansiedade na hora de prestar exames, o que a desqualificaria para o enfrentamento das agruras do mundo jurídico. Uma década mais tarde, em 1909, Inez Milholland tentou furar o bloqueio desafiando a Faculdade a rejeitar a visão sentimentalista cor-de-rosa associada às mulheres no período vitoriano, substituindo-a pela perspectiva prática e científica, permitindo a uma moça acesso ao melhor treinamento jurídico do país para poder enfrentar com desenvoltura a discriminação de gênero que ela sabia que iria encontrar futuramente no exercício da profissão. Mais uma vez, Harvard negou a candidatura e permaneceu impermeável às mulheres até 1950, quando foram admitidas as primeiras doze alunas (MORELLO, 1986: 103; DRACHMAN, 1998: 141; BLACK, 2002).

Afinal, os círculos concêntricos de desafios se sobrepunham. Nem todas as mulheres que conseguiram ser provisionadas pelos tribunais eram bacharéis em Direito e, dentre as que o eram, restava-lhes estudar em escolas de segunda grandeza, vez que os cursos de 
primeira linha relutaram em admitir a presença feminina. Mulheres cujos pais, maridos ou irmãos fossem advogados poderiam estudar Direito no resguardo familiar, usufruindo a proteção doméstica, mas aquelas que pretendessem se candidatar a uma faculdade de Direito precisavam romper com esta zona de conforto e se aventurar em ambientes impessoais dominados pelos homens, um passo que dependia do suporte de um pai ou de marido solidário. Mas também do apoio das mães, como no caso de Letitia Burlingame, que viveu na companhia da mãe em Ann Arbor durante os estudos jurídicos - a família preferiu quebrar temporariamente o núcleo de convivência a deixar a filha sozinha numa universidade em outra cidade. Além disso, concluir o curso, conseguir o diploma e arranjar trabalho na área eram coisas bem diferentes. Ada Kepley foi a primeira a graduar-se em Direito nos Estados Unidos, pela Union College of Law, em 1870. Mary Ann Shadd Cary foi a primeira afrodescendente a conseguir entrar numa escola de Direito, em 1869, mas jamais lhe permitiram receber seu diploma depois de formada. Charllotte Ray teve mais sucesso em obter o diploma de Howard, em 1872, pois era filha de um proeminente líder sindical, tornando-se, assim, a primeira negra a obter o diploma de Direito nos Estados Unidos, mas, uma década mais tarde, ela desistia do exercício da profissão diante das barreiras discriminatórias encontradas e tornava-se professora no Brooklyn, em Nova York. O magistério continuaria sendo o destino de muitas jovens formadas em Direito, pois no mundo jurídico, as instituições se fechavam ao exercício profissional de seu métier. Mulheres casadas com advogados tinham melhores oportunidades de trabalho, pois poderiam ajudar no escritório do marido (DRACHMAN, 1998: 40-59).

A aceitação da coeducação foi resultado de uma lenta e laborada conquista. Alguns professores entusiasticamente apoiavam a educação mista, mas a maioria simplesmente dizia que se demitiria se precisasse dar aulas para negros ou mulheres, como o fez o professor Spencer Miller, da Universidade da Pensilvânia em 1871 (DRACHMAN, 1998: 42). Além dos argumentos difusos sobre as esferas diferentes e a natureza dos sexos, os professores não toleravam a ideia de forçar jovens rapazes a compartilhar com moças o espaço da biblioteca, por exemplo, que, dessa forma, de templo destinado aos estudos, poderia desandar em território para distrações e flertes. Alunos e professores seguiram, além disso, ao longo de mais da metade do século, acreditando que o tempo e o 
esforço investidos no treinamento de uma mulher seriam perdidos, pois que muitas sequer faziam o curso de Direito almejando uma posição profissional permanente e, as que o pretendessem, encontrariam barreiras intransponíveis no mercado. Assim, consolidou-se entre muitos a percepção de que uma jovem em uma escola de Direito estabeleceria uma competição desnecessária, desperdiçando a vaga que seria mais bem aproveitada por um rapaz (EPSTEIN, 1981: 61-65; CHESTER, 1985: 16, 30, 44).

Quando conseguiam ingressar em um curso de Direito, sem nenhum manual de etiqueta a seguir, as mulheres precisaram construir uma nova metodologia de convivência. Em geral, evitavam comentar a hostilidade que a coeducação recebia e atravessavam a faculdade como se esse debate jamais tivesse existido. Todas se esforçavam para fazer com que os homens ao seu entorno se sentissem o mais confortavelmente possível, evitando confrontos desnecessários, até porque muitas tinham perfeita consciência da condição de pioneiras e de que seu exemplo seria seguido pelas que viriam na sequência, ou que o seu fracasso importaria no fechamento das portas entreabertas a duras penas (DRACHMAN, 1998: 54; 58).

Mas a relação longe estava de ser equitativa. Mesmo nas universidades nas quais os professores encorajavam a presença feminina, como em Michigan, no final do século XIX, não era considerado cavalheiresco expor as mulheres aos mesmos padrões de exigência estabelecidos para os rapazes (DRACHMAN, 1998: 57). Já um velho professor de Columbia, onde as mulheres apenas foram admitidas a partir de 1928, acreditava que as alunas estariam excepcionalmente bem-preparadas, porque precisaram fazer o curso na defensiva, num ambiente hostil, sendo-lhes exigido provar não apenas serem boas, mas melhores dos que os homens que ali estavam (EPSTEIN, 1981: 61-65).

Para que se tenha uma ideia do contexto, na Universidade de Boston as mulheres eram convidadas a se retirarem da sala quando sexo fosse discutido, mesmo que em perspectiva jurídica. Mulheres grávidas costumavam ser banidas dos cursos, porque seria inadequado expor os jovens estudantes a sua condição (CHESTER, 1985: 44). No século $\mathrm{XX}$, essas práticas foram aos poucos caindo em desuso, mas consolidou-se o inusitado “Ladies Day", uma tradição espraiada pelo país pela qual as mulheres eram instadas a responder todas as perguntas dirigidas à classe durante um dia inteiro. Em Harvard, 
ainda em 1961, na véspera da temida celebração, as estudantes se preparavam para serem tratadas como animais em jaulas de um zoológico em dia de piquenique com a família, especialmente nas aulas do Professor W. Barton Leach, que apenas lhes facultava a palavra nessa oportunidade, dirigindo-lhes perguntas especialmente difíceis ou constrangedoras, como as relacionadas ao sexo (NELSON, 2010, 10). A New York Un. foi, em 1967, a primeira instituição de ensino superior a proibir o "Ladies Day", o que a teria tornado um dos destinos preferidos pelas mulheres nos anos 1970 (EPSTEIN, 1981: 35).

Quando a presença feminina na advocacia começou a se tornar incontornável, a perspectiva vitoriana redesenhou a sua mensagem, dimensionando duas esferas separadas no seio da profissão jurídica: a do mundo industrial, capitalista e dos grandes negócios - a violenta e brutal arena da vida, como então se dizia -, na qual atuariam os homens; e uma dimensão distinta, da generosidade e da caridade, própria ao universo feminino. A atuação feminina era de fato mais evidente na reclusão dos escritórios e na advocacia assistencial do que no júri ou nos grandes negócios (DRACHMAN, 1998: 80).

As mulheres vitorianas se dividiram na reação a essas perplexidades. Muitas acolheram um tipo de acomodação, pela qual se acreditava que as advogadas iriam complementar a atividade dos homens, sem competir com eles. Para outras, como Sara Killgore Wertman, que pavimentou o caminho para o estudo e a prática do Direito em Michigan, as advogadas deveriam enfatizar a sua feminilidade, evitando reproduzir os mesmos padrões metodológicos e éticos dos homens, de forma a perseguir uma espécie de purificação da profissão que a promovesse a propósitos mais elevados e coletivos. Para várias associadas do Equity Club, a propósito, os homens ingressavam na profissão jurídica para auferir dinheiro e poder, algo que as mulheres deveriam transcender, em função de características que elas mesmas admitiam ser próprias do universo feminino, como a modéstia, a sensibilidade e o espírito protetor inerente à maternidade. Curiosamente, a maioria das associadas do grupo, embora integrasse a pequena vanguarda na profissão jurídica que tinha frequentado uma faculdade, tinha vindo das camadas médias da população e se identificava com o ativismo reformista, do qual participava de maneira militante, aí incluídos o sufrágio feminino, a reforma educacional, as normas menoristas e o conjunto de propostas que pretendiam revisar as leis que governavam o 
casamento, o divórcio e o estupro. Estavam, portanto, identificadas com a construção dos direitos da mulher e das crianças. Por outro lado, advogadas como Lelia Robinson, que quebrou as barreiras para a educação e a prática jurídicas em Massachusetts nos anos 1880, propugnavam que o sucesso feminino na profissão somente poderia ser alcançado se o gênero jamais fosse tomado como referencial: antes de serem mulheres advogadas deveriam ser simplesmente advogadas, sem matizar distinções diante dos outros membros dos tribunais. Para advogadas como Robinson, uma mulher poderia ser uma dama em família e privadamente, mas numa Corte deveria se comportar profissionalmente, sacrificando a sua feminilidade. Robinson não estava só: Florence Cronise acreditava que esse sentimentalismo feminino não tinha lugar na profissão jurídica e as advogadas deveriam eliminá-lo de sua prática (DRACHMAN, 1998: 64-78).

Algumas charges e romances da época dão conta da perspectiva inquietante que a figura feminina produzia no júri, estabelecendo múltiplos questionamentos. A fragilidade supostamente intrínseca da mulher a tornaria incapaz de enfrentar a dramaticidade do crime, o rigor do embate verbal? Como conciliar a convicção da necessidade de proteção da mulher, compartilhada pela sociedade vitoriana, com a sua exposição psicológica e física num ambiente de embate? A percepção romantizada da vida que se imaginava ser apanágio feminino obstruiria em que medida a aplicação do Direito? Ou, ao contrário, a feminilidade recheada de ardis seduziria sub-repticiamente os jurados para inocentar um bandido monstruoso? Numa época de arraigadas convicções cavalheirescas, contraface para a falta de autonomia das mulheres, que armas os promotores e advogados empregariam, sem serem grosseiros, para se defenderem num júri da graça e do encantamento femininos? (DRACHMAN, 1998: 84-88).

De sua parte, os depoimentos das pioneiras no Direito indicam que a atuação de júri foi em geral uma decisão difícil de ser tomada, que lhes exigiu poderosa dose de coragem pessoal e não raro apenas foi possível graças ao incentivo de colegas (juízes ou advogados que confiavam nas suas capacidades). As mulheres que passaram a enfrentar o júri, como Lelia Robinson, convergem no entendimento de que o passo amplificou o alcance de suas carreiras, mas importou em algum prejuízo para o convívio familiar. Se algumas abraçaram entusiasticamente os desafios da Sala de Júris, várias se queixavam da 
hostilidade e rudeza de juízes e advogados masculinos, os quais tentavam deliberadamente antagonizá-las ao ponto de tornar a sua presença o mais desconfortável possível. Catharine Waugh McCulloch, advogada solteira de Illinois, queixou-se, por exemplo, das bravatas de um advogado que antes do júri prometeu fazê-la limpar o chão do tribunal tão logo se confrontassem, ocasião na qual de fato acabou referindo-se a ela diversas vezes como "Kitty", como se ambos fossem amigos próximos: ela repeliu o ataque a sua reputação interpelando-o friamente e sublinhando que apenas seus familiares gozavam do privilégio de chamá-la pelo apelido, fazendo-o corar na frente do juiz. Já Kate Kane, solteira que advogava em Milwaukee desde 1878, entornou, certa feita, um copo d'água na face do juiz, que a coagia, sistematicamente, por ter tido o pedido de soltura de um cliente seu desprezado. O episódio a levou às grades e repercutiu no New York Times, que interpretou o comportamento de Kane como uma espécie de ataque histérico pelo qual se comprovaria cabalmente a inadequação feminina para o ambiente do júri. Não ocorreu aos jornalistas indagar-se sobre o abuso de poder do juiz (DRACHMAN, 1998: 91-3).

A relação com a imprensa era outro componente delicado da equação. A maior parte dos jornalistas nutria estranhamento em face do desempenho feminino no mundo jurídico. Não raro, havia hostilidade. De qualquer forma, ávidos por notícias que despertassem a curiosidade dos leitores, os jornais seguiam cada movimento das mulheres, o que as obrigava a lidar com a questão relativa ao excesso de evidência. Com tanta pressão, os mínimos detalhes tornavam-se relevantes, de forma que debater o código de vestimenta assumia dimensão estratégica. O recomendável era usar conjuntos bem-cortados, em preto, sem decotes acentuados, elegantes, mas confortáveis (de maneira a permitir liberdade de movimentos), acentuados por laços e joias comedidas. A indumentária deveria transmitir a gravidade de um agente do Direito, sem deixar de preservar a feminilidade. Exageros e futilidades da moda precisavam ser evitados. O grande dilema, já comentado, girava em torno do uso do chapéu (DRACHMAN, 1998: 95).

O fardo da dupla jornada - isto é, a difícil fórmula que permite conciliar vida profissional com a familiar e a doméstica - já estava posto para as advogadas do final do século XIX. As senhoras do Equity Club descreviam rotinas estressantes, que se emaranhavam em múltiplas tarefas, desde detalhes da alimentação ou educação dos 
filhos pequenos, até causas de impacto defendidas nas Cortes, passando pela redação de artigos ou ensaios para revistas e jornais e pelas orientações ao jardineiro, dentre outras coisas. Mesmo com maridos que as apoiavam e as estimulavam, algumas temiam estar negligenciando os filhos e o próprio companheiro, tendo se debatido com este drama de consciência por anos. Mais da metade das associadas ao Equity Club era composto de senhoras casadas. Dentre as solteiras, muitas eram jovens e tenderiam a buscar o matrimônio. Algumas pioneiras do século XIX resolveram, entretanto, abandonar a profissão depois de casadas, ou porque precisavam cuidar de parentes adoentados. Mas a preocupação em torno dos problemas de saúde advindos da intensa carga de tarefas derivada da dupla jornada estava também posta e algumas precisaram se afastar da profissão para se recuperar do esgotamento físico. Um censo de 1890 identificou que $14 \%$ das advogadas praticantes eram viúvas ou divorciadas. Censos elaborados nos anos 1930 e 1940 mostraram que a taxa de advogadas casadas continuava mais alta do que a de médicas casadas, mas que as operadoras do Direito estavam adequando o tamanho de suas famílias ao volume de suas atividades profissionais: cada vez mais advogadas tinham apenas um, ou no máximo dois filhos (DRACHMAN, 1998: 98-100; 180).

No século XX, o aumento do número de faculdades de Direito, o avanço do conceito de educação mista (acelerado pela Primeira Guerra Mundial) e a instituição dos cursos noturnos, permitiu a ampliação do contingente de estudantes mulheres, abrindo ainda o Direito para grupos de imigrantes e setores das classes trabalhadoras. Surgiu uma nova geração de advogadas, algumas das quais ativistas mais radicais em prol de bandeiras como o aborto e a reforma do sistema prisional, ou comprometidas com a prestação de serviços jurídicos gratuitos aos pobres (DRACHMAN, 1998: 136).

Apesar do pioneirismo registrado no século XIX, a primeira onda significativa de mulheres no Direito aconteceu nos anos 1920. Em 1909 havia 205 advogadas nos Estados Unidos, contingente que saltou para 1.171 em 1920. Os anos 1920 foram tempos de oportunidades para as mulheres. A queda da barreira para a advocacia em quase todos os Estados coincidia com a adoção do sufrágio feminino. Os cursos de Direito se tornaram bem mais receptivos às mulheres. A depressão econômica dos anos 1930, contudo, barrou o seu progresso na conquista de espaços, pois os postos de trabalho passaram a ser muito 
mais disputados. Por outro lado, também criou algumas oportunidades, como no âmbito do trabalho voluntário e assistencial, no qual, em época de crise, muitas se realizaram e encontraram clientes dispostos a arriscar serem juridicamente orientados por uma mulher (CHESTER, 1985: 9-15).

Nos anos 1920, as mulheres também começaram a ingressar nas carreiras públicas. Em função da crise econômica e da política desenvolvimentista do New Deal, apesar das discriminações, de perceberem menores salários e de receberem funções com menos visibilidade, o serviço púbico federal ofereceu às mulheres melhores condições do que elas poderiam encontrar em qualquer outro ramo do Direito. Ainda assim, essas oportunidades se dispunham em nichos específicos, tais como a mediação de conflitos, o controle da atividade industrial, a redação do esboço de leis e regulamentos, o auxílio na formulação de políticas públicas e, sobretudo, o Serviço Social. Posições menos visíveis, certamente, mas nem por isso desprezíveis. A adoção do sufrágio feminino fez com que os partidos organizassem comitês de mulheres, investindo na cooptação e na formação de lideranças, algumas das quais encontraram posições na administração federal como retribuição pelo seu engajamento. $\mathrm{Na}$ linha de frente, entretanto, a presença feminina era pouco perceptível. Por volta de 1935, o Procurador Federal do Distrito de Columbia, Leslie Garnett, explicou que as mulheres não tinham a frieza necessária para o trabalho acusatório da Promotoria, motivo pelo qual não seriam jamais ali admitidas (TANI, 2012).

No Canadá, Emily Murphy foi nomeada magistrada junto à Edmonton Municipal Court pelo governo de Alberta, em 1916. Foi a primeira em profissões jurídicas públicas no Império Britânico. A Província era uma das três primeiras a reconhecer o direito ao voto feminino, naquele mesmo ano. Em seu julgamento inaugural, um advogado em vias de perder a causa declarou que a decisão da nova magistrada não seria válida, porque juridicamente Murphy não poderia ser considerada uma "pessoa”, apoiando-se em uma decisão de um tribunal inglês de 1876, que ainda não havia sido revista, apesar de terse tornado obsoleta. A apelação opressiva foi remetida à Corte Superior de Alberta, que confirmou a nomeação de Murphy e a validade da sentença. O caso acabou dando argumentos para a causa feminista e a partir daí Murphy foi lançada por movimentos sufragistas, jornais e lideranças como nome a ser qualificado ao Senado. Embora a 
Província houvesse garantido a Murphy a autoridade para o exercício da magistratura, ela entendeu que a questão se dirigia ao estatuto das mulheres em seu conjunto e peticionou, juntamente com outras cinco ativistas, mais tarde reconhecidas como as Famous Five (Nellie McClung, Irene Parlby, Louise McKinney and Henrietta Muir Edwards), à Suprema Corte, no caso que ficou conhecido como Edwards v. Canada. Em 1928, a Suprema Corte rejeitou a petição, mas um ano mais tarde o Judicial Committee of the British Privy Council garantiu um apelo em seu favor. Finalmente, em 18 de outubro de 1927, a Suprema Corte repeliu em definitivo o entendimento de que a palavra "pessoa" não incluía também as mulheres. Dentre as consequências da decisão, Cairine Reay Mackay Wilson foi indicada para integrar o Senado do Canadá em 15 de fevereiro de 1930, quebrando uma longa tradição de exclusividade masculina na Câmara Alta. Wilson tornou-se depois a primeira delegada do país na Assembleia-Geral da ONU, em 1949. Em 2009, as Famous Five foram nomeadas postumamente senadoras honorárias. Outro desdobramento fundamental da decisão garantiu à Suprema Corte canadense o poder de entender a Constituição como uma "árvore viva" e de reescrevê-la a partir de suas decisões. Portanto, no Canadá, o exercício por mulheres das profissões jurídicas, especificamente, da magistratura, emergiu imbricado de forma explícita à questão do voto feminino e do acesso ao Parlamento e impactou o modo como a própria Constituição passou a ser percebida (BENOIT, 2000; REID, 2012).

Durante a Segunda Guerra Mundial, aumentou o número de estudantes do sexo feminino e surgiram empregos temporários, mas, depois de encerrado o tormentoso conflito, os postos de trabalho foram devolvidos aos homens. De um modo geral, a educação das mulheres nos anos 1940 e 1950 não focava as carreiras, mas o desenvolvimento de habilidades para o meio doméstico. As mulheres conseguiram consolidar carreiras jurídicas mais frequentemente apenas a partir dos anos 1960, quando uma legislação antidiscriminação começou a ser implementada. Os anos 1970 ofereceram grandes oportunidades às mulheres (CHESTER, 1985: 9-15). Mesmo assim, os analistas tendem a concordar que no mundo das grandes e poderosas firmas de advocacia, a falta de equidade entre os gêneros ainda persiste nos Estados Unidos, assim como no Canadá (EPSTEIN, 1981; BOWMAN, 1998: 171). Parte dos teóricos sustenta a prevalência de desníveis 
em função de fenômenos como o mommy track, isto é, os efeitos desmobilizadores sobre as carreiras femininas trazidos pela maternidade (SCHWARTZ, 1989). Bowman (1998: 175), contudo, está entre os autores que encontram dificuldades em reconhecer atualmente uma segregação de trabalho como resultado de discriminação de gênero no âmbito do conjunto da profissão jurídica.

Atualmente, as feministas discordam entre si sobre a pertinência da diferenciação da natureza do trabalho jurídico de homens e mulheres. Algumas temem o risco de reforço de estereótipos essencialistas, que desconsiderariam as particularidades individuais entre as mulheres: há quem possa ser mais carreirista e materialista, há quem seja mais engajado em perspectivas humanistas e acalente preocupações sociais. O mesmo acontece com homens e mulheres. Estudos sobre a advocacia de mediação, por exemplo, não revelam diferenças de estilo entre homens e mulheres, não obstante as advogadas estarem super-representadas neste campo (HARRINGTON; RIFKIN, 1989). Para além disso, as evidências empíricas que comprovariam a validade dessa distinção estão longe de serem esmagadoras (BOWMAN, 1998: 173). Ainda assim, autores como Suzanna Sherry (1986) e Menkel-Meadow (1985, 1986), sustentam que as julgadoras mulheres exibem preocupação maior com o contexto e com a comunidade, do que com a abstração e a rigidez das leis, como em teoria tenderia a fazer a maioria dos homens.

Todavia, tais teorias ainda carecem de validação científica. Faltam, estudos em larga escala sobre a jurisprudência praticada, bem como sistematizações amplas e aprofundadas de entrevistas com mulheres operadoras do Direito. Finalmente, não é improvável que conclusões captadas para uma geração já não sejam mais aplicáveis a gerações seguintes, pois há elementos conjunturais e contextuais da sociedade que podem ser determinantes e que estão em permanente movimentação.

\section{Referências}

APPLEWHITE, Hariet B.; LEVY, Darline G. Responses to political Activism of Women of the People in Revolutionary Paris, 1789-1793. In: Women and the Structure of Society - selected research from the fifth Berkshire Conference on the History of Women, edited by Barbara J. Harris and Joann K. McNamara. Duke Press Policy Studies, 1984. 
AXT, Gunter. Considerações sobre as Memórias do General Vieira da Rosa (1893-1930). Pelotas, Revista Memória em Rede, Vol. 6, n. 10, 2014. http://www2.ufpel.edu.br/ich/ memoriaemrede/beta-02-01/index.php/memoriaemrede/article/view/206

. Histórias de Vida, vol. 3. Mulheres do Direito, mulheres no Ministério Público. Florianópolis: Memorial do MPSC/PGJ-SC, 2015.

BACKHOUSE, Constance. To Open the Way for Others of My Sex: Clara Brett Martin's Career as Canada's First Woman Lawyer. Canadian Journal of Women and the Law Vol $1,1985$.

. Clara Brett Martin: Canadian Heroine or Not? Canadian Journal of Women and the Law, Vol. 56, 263, 1992.

BEAUVOIR, Simone de. O segundo sexo. Rio de Janeiro: Nova Fronteira, 2009.

BENOIT, Monique, Are Women Persons? The 'Persons' Case. Archived at Library and Archives Canada. N. 119, 2000. https://www.collectionscanada.gc.ca/ publications/002/015002-2100-e.html

BROOKS, Kim; MATHEN, Carissima (Ed.). Women, Law, and Equality: A Discussion Guide. Toronto: Irwin Law, 2010.

BERGSON, Henri. O pensamento e o movente. São Paulo: Martins Fontes, 2006.

BLACK, Barbara Aronstein. Something to Remember, Something to Celebrate: Women at Columbia Law School. Columbia Law Review, vol. 102, n. 6, p. 1451-146, out. 2002.

BOURDIEU, Pierre. A dominação masculina. Rio de Janeiro: Bertrand do Brasil, 1999.

BOWMAN, Cynthia Grant. Bibliographical Essay: Women and the Legal Profession. Journal of Gender, Social Policy \& The Law, v. 7, p. 149, 1998.

CATALYST. Catalyst Quick Take: Women in Law in Canada and the U.S. New York: Catalyst, 2015. http://www.catalyst.org/knowledge/women-law-canada-and-us

CERQUEIRA, Fábio Vergara. Evidências iconográficas da participação de mulheres no mundo do trabalho e na vida intelectual e artística na Grécia Antiga. Campinas: IV Encontro de História da Arte - IFCH/Unicamp, 2008, p. 151-185.

CHESTER, Ronald. Unequal Access: women Lawyers in Changing America. Amherst: Bergin; Garvey Publishers, Inc., 1985.

COLLING, Ana Maria. As primeiras médicas brasileiras: mulheres à frente de seu tempo. Fronteiras, Dourados, MS, v. 13, n. 24, p. 169-183, jul./dez. 2011.

COSSMAN, Brenda; KLINE, Marlee. 'If not now when': Feminism and Anti-Semitism Beyond Clara Brett Martin. Canadian Journal of Women and the Law, Vol. 5, 298, 1992.

Martin, Clara Brett. Dictionary of Canadian Biography. University of Toronto Press. 1979-2016. http://www.biographi.ca/en/bio/martin_clara_brett_15E.html 
DENIKE, Margaret; FARADY, Fay; STEPHENSON, M. Kate (Ed.) Making Equality Rights Real: Securing Substantive Equality under the Charter Toronto: Irwin Law, 2009.

DRACHMAN, Virginia G. Sisters in Law: women lawyers in modern American History. Cambridge, Massachusetts: Harvard University Press, 1998.

EPSTEIN, Cynthia F. Women in Law: Basic Books, 1981.

GORECKI, Meg. Legal Pioneers: Four of Illinois. First Women Lawyers. Illinois Bar Journal. p. 510-515, out. 1990.

GROSSBERG, Michael. Institutionalizing Masculinity: The Law as a Masculine Profession. In: Mark C. Carnes; Clyde Griffen (Ed.), Meanings for Manhood: Constructions of Masculinity in Victorian America. Chicago: University of Chicago Press, 1990.

GUATTARI, Félix. Caosmose: um novo paradigma estético. Rio de Janeiro: Ed. 34, 1992.

HARRINGTON, Christine B.; RIFKIN, Janet. The Gender Organization of Mediation: Implications for the Feminization of Legal Practice. Madison: Institute for Legal Studies, University of Wisconsin-Madison Law School, 1989.

HESPANHA, António Manuel. Caleidoscópio do Antigo Regime. São Paulo: Ed. Alameda, 2012.

JELIN, Elizabeth. Memorias en Conflicto. Revista Puentes, n. 1, Buenos Aires e Madrid, 2000 .

KAY, Fiona M. Crossroads to Innovation and Diversity: The Careers of Women Lawyers in Quebec. McGill Law Journal, v. 47, p. 699-745, 2002,

MALUF, Marina; MOTT, Maria Lúcia. Recôndidos do mundo feminino. In: SEVCENKO, Nicolau. História da vida privada no Brasil, v. 3, São Paulo: Cia. Das Letras, 1998.

MARTIN-FUGIER, Anne. Os ritos da vida privada burguesa. In: PERROT, Michelle (Org.) História da Vida Privada. Da Revolução Francesa à Primeira Guerra. v. 4, p. 193-261, São Paulo: Ed. Cia das Letras, 1991.

MENKEL-MEADOW, Carrie. Portia in a Different Voice: Speculations on a Woman's Laryering Process, BERKELEY WOMEN'S LJ. 39, 1985.

. The comparative sociology of woman lawyers: the "feminization" of legal profession. Osgoode Hall Law Journal, Toronto, v. 24, n. 4, p. 897-919, 1986.

MORELlO, Karen B. The Invisible Bar: The women lawyer in America, 1639 to the present. New York: Random House, Inc., 1986.

MOSSMAN, Mary Jane. The first women lawyers: "piecemeal progress and circumscribed success”. Osgoode hall law journal, v. 45, n. 2, p. 379-396, York University, Toronto, summer 2007. 
NELSON, Jessica Louise. Gender and Justice: the experience of Female Lawyers in Indianapolis. A Thesis Presented to the Department of History and Anthropology. Indianapolis: Butler University, mai. 2010.

PAGLIA, Camille. Personas sexuais: arte e decadência de Nefertite a Emily Dickinson. São Paulo: Ed. Companhia das Letras, 1990. . Entrevista à revista Veja, 1992.

. Imagens cintilantes: uma viagem através da arte desde o Egito a Star Wars. Rio de Janeiro: Ed. Apicuri, 2014.

PATAI, Daphne. História oral, feminismo e política. São Paulo: Letra e Voz, 2010.

PERROT, Michelle. Os excluídos da história: operários, mulheres, prisioneiros. São Paulo: Ed. Paz e Terra, 2010.

REID, Scott. The court case that changed everything. How Canada's courts have misread a historic ruling, giving themselves the power to rewrite the Constitution. National Post, 22 October, 2012. http://nationalpost.com/opinion/scott-reid-the-court-case-thatchanged-everything

SANSEVERINO, Patrícia; SOUTO, Cíntia Vieira; TORRE, Márcia de la (Org.). Histórias de Vida do Ministério Público do Rio Grande do Sul: olhar feminino. Porto Alegre: Memorial do MPRS, 2005.

SARLO, Beatriz. Tempo Passado: cultura da memória e guinada subjetiva. São Paulo: Companhia das Letras, Belo Horizonte: UFMG, 2007.

SCHWARTZ, Felice N. Management Women and the New Facts of Life. Harvard Business Journal, jan.-fev. 1989.

SHERRY, Suzanna. Civic Virtue and the Feminine Voice in Constitutional Adjudication, 72 VA. L. REV. 543, 1986.

STANFILL, Francesca. Woman warrior: Sexual Philosopher Camille Paglia jousts with politically correct. New York Magazine, 4 mar. 1991.

TANI, Karen M. Portia's Deal, 87 Chi.-Kent. L., rev. n. 549, Chicago, 2012. Disponível em: http://scholarship.law.berkeley.edu/facpubs/1648.

ŽIŽEK, Slavoj. Em defesa das causas perdidas. São Paulo: Boitempo, 2011.

\section{Notas}

1 Colaborador Diversitas/USP, São Paulo, SP. Pós-doutorado PPG Direito, Universidade Federal de Santa Catarina, UFSC, Florianópolis, Brasil.gunteraxt@gmail.com 